\title{
Effectiveness and safety of citicoline in mild vascular cognitive impairment: the IDEALE study
}

This article was published in the following Dove Press journal:

Clinical Interventions in Aging

4 February 2013

Number of times this article has been viewed

\section{Antonino Maria Cotroneo' \\ Alberto Castagna ${ }^{2}$ \\ Salvatore Putignano 3 \\ Roberto Lacava ${ }^{2}$ \\ Fausto Fantò ${ }^{4}$ \\ Francesco Monteleone ${ }^{5}$ \\ Filomena Rocca ${ }^{2}$ \\ Alba Malara ${ }^{6}$ \\ Pietro Gareri ${ }^{2}$}

'ASL 2 Turin, Piedmont, ${ }^{2}$ Elderly Health Care, Ambulatory Center for Dementia, ASP Catanzaro,

Calabria, ${ }^{3} \mathrm{ASL}$ Napoli I, Campania, ${ }^{4}$ University Hospital Orbassano,

Turin, Piedmont, ${ }^{5}$ Regina Margherita Hospital, Rome, ${ }^{6}$ Nursing Home S Domenico Lamezia Terme, ASP Catanzaro, Calabria, Italy

\section{Video abstract}

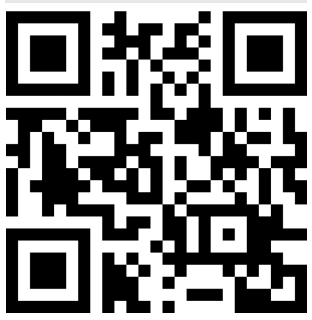

Point your smartphone at the $\mathrm{QR}$ code to the left. If you have a QR code reader the video abstract will appear. Or use: http://dvpr.es/ Vfeb4Q

Correspondence: Antonino Maria Cotroneo

ASL 2 Turin, Corso Svizzera I64,

I0I49 Turin, Italy

Tel +39 0l I4393767

Fax +39 0I l4393770

Email geriatrix।@libero.it

Pietro Gareri

Elderly Health Care,

Ambulatory Center for Dementia,

ASP Catanzaro, Via Spasari, 3

88100 Catanzaro, Italy

Tel +3909 6I 703361

Fax +39096I725095

Email pietro.gareri@alice.it
Background: The studio di intervento nel decadimento vascolare lieve (IDEALE study) was an open multicenter Italian study, the aim of which was to assess the effectiveness and safety of oral citicoline in elderly people with mild vascular cognitive impairment.

Methods: The study was performed in 349 patients. The active or citicoline group was composed of 265 patients and included 122 men and 143 women of mean age $79.9 \pm 7.8$ years selected from six Italian regions. Inclusion criteria were age $\geq 65$ years, Mini-Mental State Examination (MMSE) score $\geq 21$, subjective memory complaints but no evidence of deficits on MMSE, and evidence of vascular lesions on neuroradiology. Those with probable Alzheimer's disease were excluded. The control group consisted of 84 patients, including 36 men and 48 women of mean age $78.9 \pm 7.01$ (range 67-90) years. Patients included in the study underwent brain computed tomography or magnetic resonance imaging, and plasma dosage of vitamin B12, folate, and thyroid hormones. Functional dependence was investigated by scores on the Activities of Daily Living (ADL) and Instrumental Activities of Daily Living (IADL) scales, mood was assessed by the Geriatric Depression Scale (GDS), and behavioral disorders using the Neuropsychiatric Inventory scale. Comorbidity was assessed using the Cumulative Illness Rating Scale. An assessment was made at baseline (T0), after 3 months (T1), and after 9 months (T2, ie, 6 months after T1). The main outcomes were an improvement in MMSE, ADL, and IADL scores in the study group compared with the control group. Side effects were also investigated. The study group was administered oral citicoline $500 \mathrm{mg}$ twice a day throughout the study.

Results: MMSE scores remained unchanged over time $(22.4 \pm 4$ at T0; $22.7 \pm 4$ at $\mathrm{T} 1 ; 22.9 \pm 4$ at T2), whereas a significant difference was found between the study and control groups, both in $\mathrm{T} 1$ and in T2. No differences were found in ADL and IADL scores between the two groups. A slight but not statistically significant difference was found in GDS score between the study and control groups $(P=0.06)$. No adverse events were recorded.

Conclusion: In this study, citicoline was effective and well tolerated in patients with mild vascular cognitive impairment. Citicoline activates biosynthesis of phospholipids in neuronal membranes, increases brain metabolism as well as norepinephrine and dopamine levels in the central nervous system, and has neuroprotective effects during hypoxia and ischemia. Therefore, citicoline may be recommended for patients with mild vascular cognitive impairment.

Keywords: citicoline, vascular mild cognitive impairment, elderly, safety, effectiveness

\section{Introduction}

The number of people aged 65 years and over with mild vascular cognitive impairment is continuing to increase. It is widely known that vascular disease can reduce cerebral perfusion, causing oxidative stress and neurodegeneration. Vascular disease has also been reported to accelerate atrophy and results in white matter abnormalities, asymptomatic infarct, inflammation, and reduced glucose metabolism, cerebral blood 
flow, and vascular density. ${ }^{1,2}$ The elderly brain is also more susceptible to hypotension and pump failure as a result of cardiac arrhythmia, and congestive heart failure. Delivery of oxygen to tissues and other metabolic exchanges are impeded by increased thickness of vessel walls and widespread état criblé, with enlargement of perivascular Virchow-Robin spaces, resulting from tortuosity of elongated arterioles. ${ }^{2}$ Therefore, cerebral vascular disease may cause impairment in activities of daily living and frequent requests for intervention by health services.

Cytidine- $5^{\prime}$-diphosphate (CDP) choline is an endogenous compound normally produced by the body, and in pharmaceutical form is known as citicoline. Citicoline inhibits apoptosis associated with cerebral ischemia and in several models of neurodegeneration has been able to potentiate neuroplasticity. It is a natural precursor of phospholipid synthesis, or rather serves as a choline source in the metabolic pathways for biosynthesis of acetylcholine and neuronal membrane phospholipids, mainly phosphatidylcholine..$^{3-6}$

Animal studies suggest that CDP choline may protect cell membranes by accelerating resynthesis of phospholipids. CDP choline may also attenuate the progression of ischemic cell damage by suppressing the release of free fatty acids. ${ }^{7,8}$ Furthermore, citicoline has been shown to increase cerebral metabolism and noradrenaline and dopamine levels in the central nervous system. ${ }^{9-11}$ Numerous experimental stroke studies using citicoline have reported an improved outcome and reduced infarct size in models of ischemic and hemorrhagic stroke. Citicoline has been studied worldwide in both ischemic and hemorrhagic stroke with excellent safety, and with possible efficacy found in several clinical trials. ${ }^{12}$ Citicoline has a number of therapeutic actions, including:

- neuroprotective effects in situations of hypoxia and ischemia

- improvement of attention, learning, and memory performance in animal models of brain aging

- restoration of mitochondrial ATPase and membrane $\mathrm{Na}^{+} / \mathrm{K}^{+}$ATPase activity

- inhibition of activation of phospholipase $\mathrm{A}_{2}$ and accelerated reabsorption of cerebral edema in various experimental models. ${ }^{11,13-20}$

Pharmacokinetic studies have suggested that citicoline is well absorbed and bioavailable following oral dosing. It can be used not only in cognitive impairment, but also in Parkinson's disease, head trauma, and amblyopia. ${ }^{17}$ Table 1 reports the possible clinical uses of citicoline. The studio di intervento nel decadimento vascolare lieve (IDEALE study) reported here was an open-label, multicenter Italian study, the aim of which
Table I Clinical use of citicoline

- Cerebrovascular disease

- Head trauma of varying degrees

- Cognitive disorders of diverse etiology

- Glaucoma

- Ambliopia

- Parkinson's disease

was to assess the effectiveness and safety of oral citicoline in elderly people with mild vascular cognitive impairment.

\section{Patients and methods}

This study was performed in 387 elderly patients selected from six Italian regions (Calabria, Campania, Lazio, Liguria, Piedmont, Veneto). Inclusion criteria were: age $\geq 65$ years; Mini-Mental State Examination (MMSE) $\geq 21$; subjective memory complaints but no evidence of deficits on MMSE; and evidence of vascular lesions on neuroradiology. Those with probable Alzheimer's disease were excluded.

Patients included in the study underwent brain computed tomography or magnetic resonance imaging of the brain, plasma dosage of vitamin $\mathrm{B}_{12}$, folate and thyroid hormones (thyroid stimulating hormone, free triiodothyronine3, free tetraiodothyronine, thyroid peroxidase antibodies, and thyroglobulin antibodies). Functional dependence was investigated by scores on the ADL (Activities of Daily Living) and IADL (Instrumental Activities of Daily Living) scales, mood was investigated by the GDS (Geriatric Depression Scale), and behavioral disorders by the Neuropsychiatric Inventory Scale. Comorbidity was assessed using the Cumulative Illness Rating Scale, a test assessing the number and severity of diseases in individual patients. All patients gave their written informed consent.

A total of 349 patients met our criteria and completed the study. They were assigned to open-label treatment with oral citicoline $500 \mathrm{mg}$ twice a day in a fasting state or to no treatment (controls).

The treatment group included 265 patients, being 122 men and 143 women of mean age $79.9 \pm 7.8$ (range 65-94) years. The control group included 84 patients, being 36 men and 48 women of mean age 78.9 \pm 7.01 (range 67-90) years (Figure 1). Twenty-one patients were excluded on suspicion of having Alzheimer's disease, two died before the end of the study, and 15 dropped out (Figure 1). The main characteristics of the study cohort are shown in Table 2 . An assessment was made at baseline (T0), after 3 months (T1), and after 9 months (T2, ie, 6 months after T1). The main outcomes were changes in MMSE, ADL, and IADL scores in the study group compared with controls. Side effects were also investigated. 


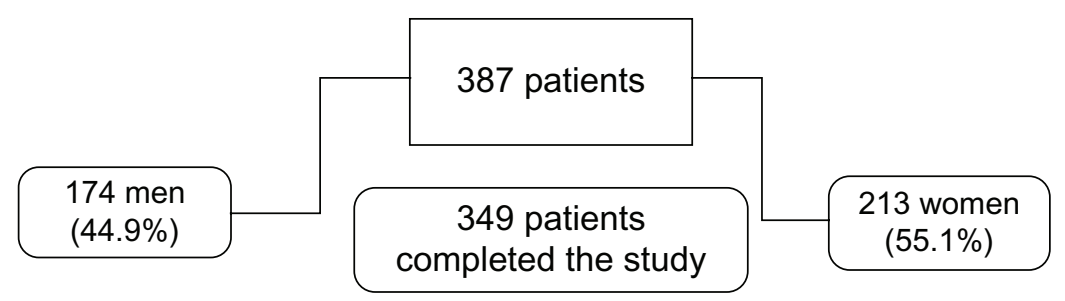

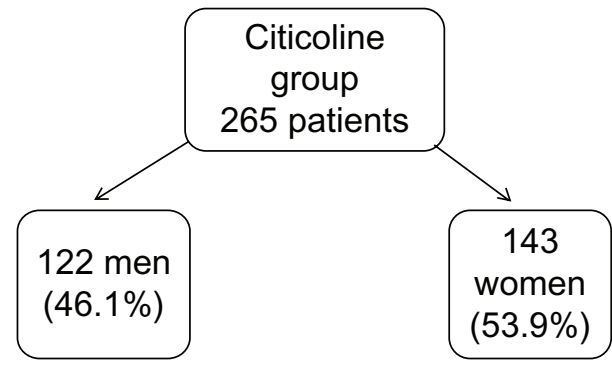

Mean age $79.9 \pm 7.8$ years old (range 65-94)

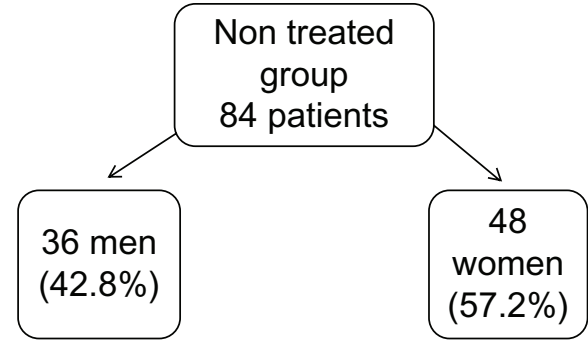

Mean age $78.9 \pm 7.01$ years old
(range $67-90$ )

Figure I Cohort gender flow chart.

\section{Statistical analysis}

The data are expressed as the mean \pm standard deviation, and comparisons between groups were made using the Student's $t$-test or the Chi-square test, as appropriate. Repeated-measures analysis of variance was used to assess the difference in changes between values at baseline and at $\mathrm{T} 1$ and T2. Significant differences were assumed to be present at $P<0.05$. All analyses were performed using the Statistical Package for the Social Sciences software program version 18.0 for Windows (SPSS Inc, Chicago, IL).

Table 2 Main characteristics in the cohort studied

\begin{tabular}{|c|c|c|}
\hline Citicoline group & Non treated group & $\mathbf{P}$ \\
\hline - 265 pts & - 84 pts & \\
\hline - Mean age $79.9 \pm 7.8$ years old (range $65-94)$ & - Mean age $78.9 \pm 7.01$ years old (range $67-90)$ & ns \\
\hline - 122 men (46. I\%), I 43 women (53.9\%) & - 36 men (42.8\%), 48 women $(57.2 \%)$ & ns \\
\hline - Education $6.1 \pm 3.8$ years & - Education $5.9 \pm 2.6$ years & ns \\
\hline - Smokers (5.6\%) & - Smokers (6.1\%) & ns \\
\hline - ADL $4.0 \pm 1.8$ & - $\mathrm{ADL} 4.1 \pm 1.6$ & ns \\
\hline - IADL $5.6 \pm 1.2$ & - IADL $5.7 \pm 2.3$ & ns \\
\hline - GDS $5.6 \pm 2.2$ & - GDS $5.8 \pm 1.4$ & ns \\
\hline - CIRS $3.2 \pm 1.3$ & - CIRS $3.4 \pm 1.8$ & ns \\
\hline - NPI $8.4 \pm 4.5$ & - NPI $9.2 \pm 2.1$ & ns \\
\hline - Comorbidities & - Comorbidities & \\
\hline - Hypertension (75\%) & - Hypertension (77\%) & ns \\
\hline - Osteoarthritis (72\%) & - Osteoarthritis (70\%) & ns \\
\hline - Heart disease (43\%) & - Heart disease (38\%) & ns \\
\hline - Diabetes (35\%) & - Diabetes (37\%) & ns \\
\hline - COPD (I5\%) & - COPD (I8\%) & ns \\
\hline - Depression (20\%) & - Depression (23\%) & ns \\
\hline - Stroke (15\%) & - Stroke (II\%) & ns \\
\hline - Drugs & - Drugs & \\
\hline - Cardiovascular drugs* (84\%) & - Cardiovascular drugs* (8I\%) & ns \\
\hline - NSAIDs** (48\%) & - NSAIDs** (52\%) & ns \\
\hline - Antidiabetics (35\%) & - Antidiabetics (37\%) & ns \\
\hline - Antidepressants (20\%) & - Antidepressants (23\%) & ns \\
\hline - Others (20\%) & - Others (24\%) & ns \\
\hline
\end{tabular}

Notes: *Antihypertensive drugs, antiaggregants, diuretics, nitrates, $\beta$-blockers, digoxin; **Non-steroidal anti-inflammatory drugs.

Abbreviations: ADL, activities of daily living; CIRS, cumulative illness rating scale; COPD, chronic obstructive pulmonary disease; GDS, geriatric depression scale; IADL, instrumental activities of daily living; NPI, neuropsychiatric inventory scale; ns, non significant. 
Table 3 Citicoline group

\begin{tabular}{llr}
\hline & Patients & $\% *$ \\
\hline Campania & 79 & 29.9 \\
Calabria & 66 & 24.9 \\
Lazio & 22 & 8.3 \\
Liguria & 30 & 11.3 \\
Piemonte & 48 & 18.1 \\
Veneto & 20 & 7.5 \\
Total & 265 & 100 \\
South Italy & 167 & 63.1 \\
North Italy & 98 & 36.9 \\
Total & 265 & 100 \\
\hline
\end{tabular}

Note: *Percent determined on the overall patients (citicoline group) involved in the study.

\section{Results}

Campania and Calabria were the regions with the most number of patients in the citicoline group (79 and 66, respectively), and 167 patients were from Southern Italy and 98 from Northern Italy (Table 3 ). The main neuroradiological findings are reported in Table 4, showing cortical atrophy to be present in $85 \%$ of cases and periventricular white matter hypodensities in $60 \%$.

The MMSE score in the treated group remained essentially unchanged over time $(22.4 \pm 4$ at T0; $22.7 \pm 4$ at T1; $22.9 \pm 4$ at T2). A mild improvement of 0.5 points on average was found during the 9 months of the study, but without significant regional differences. Improvement in MMSE score was more evident in patients from Southern Italy. The untreated group showed a decline in MMSE score over the 9 months (21.5 at T0; 20.4 at T1 and 19.6 at T2; -1.9 points between T0 and T2). No differences were found for ADL and IADL scores between the two groups. Positive changes in ADL scores were slightly better in patients from Northern Italy, but were essentially superimposable. Similar results were evident across the regions (albeit slightly better in Liguria). The final IADL scores were superimposable and showed only slight improvement.

Figure 2 shows the ADL, IADL, and MMSE scores for the treated group. We also looked for possible differences in ADL, IADL, and MMSE scores according to age group (young-old

Table 4 Neuroradiological findings for all patients in the present study

- Cortical atrophy (85\%)

- Periventricular white matter hypodensity (CT) (40\%)

- Multiple microinfarcts (25\%)

- Periventricular white matter hyperintensities (MRI), punctuate or confluent (20\%)

- Lacunar infarcts $(20 \%)$

- Old infarcts (I5\%)

- Any focal lesion (12\%)

Abbreviations: CT, computed tomography; MRI, magnetic resonance imaging. age 65-74 years, old-old age 75-84 years, very-old age $\geq 85$ years). Young-old patients showed better performance, but not significantly different from that in the other age groups (Figure 3). A significant difference in MMSE scores was found between the treatment and control groups at T1 $(P<0.0001)$ and T2 $(P<0.0001)$ time points (Figure 4A and 4B), but not between $\mathrm{T} 0$ and $\mathrm{T} 1$ or between $\mathrm{T} 0$ and $\mathrm{T} 2$ (Figure 4B). No differences in ADL and IADL scores were found between the two groups (Figure 5). A slight difference in GDS score was found between the study and control groups $(P=0.06$, not statistically significant, data not shown). No significant adverse events were recorded over time. Occasional excitability or restlessness was found in $5.6 \%$ of cases, and digestive intolerance and self-limiting headaches in $4.5 \%$ and $3.6 \%$ of cases, respectively.

\section{Discussion}

This study shows that citicoline is effective and safe in the treatment of mild vascular cognitive impairment. The treated group showed improvement in MMSE scores, with an increase of 0.5 points shown over the course of the study. CDP choline may attenuate the progression of ischemic cell damage by suppressing the release of free fatty acids. ${ }^{8}$ A number of studies have also shown that citicoline appears to be a drug able to provide "safe" neuroprotection by enhancing protective endogenous pathways. ${ }^{13,21}$ These properties suggest that citicoline can be recommended for use in patients with vascular cognitive impairment, vascular dementia, or Alzheimer's disease with significant cerebrovascular disease. It seems to have a beneficial impact on several cognitive domains. ${ }^{22}$ In another study, we demonstrated the efficacy of citicoline in post-ischemic cerebrovascular disease, but we used intravenous citicoline in saline. ${ }^{23}$

Our present study of citicoline is one of the few trials conducted for a period longer than 6 months. Its bioavailability has been very good following oral administration. ${ }^{9,15,17}$ With regard to its mechanism of action, we believe that the most pronounced benefits of treatment with citicoline, ie, activation of biosynthesis of phospholipids in neuronal membranes, increase in brain metabolism, and neuroprotective effects during hypoxia and ischemia, are likely to be accrued with prolonged use. This is confirmed by the positive results in our treated group and by the decrease in MMSE scores in our control group at only 9 months. The positive effects on mood probably derive from the increase in noradrenaline and dopamine levels in the brain attributable to citicoline. 


\begin{tabular}{llll}
\hline & T0 & T1 (3 months) & T2 (9 months) \\
\hline ADL & $4.0 \pm 1.8$ & $4.1 \pm 1.7$ & $4.2 \pm 1.7$ \\
IADL & $5.6 \pm 3.2$ & $5.8 \pm 3.2$ & $5.9 \pm 3.1$ \\
MMSE & $22.4 \pm 4.0$ & $22.7 \pm 4.0$ & $22.9 \pm 4.0$ \\
\hline
\end{tabular}

\begin{tabular}{|c|c|c|c|c|c|c|}
\hline & \multicolumn{2}{|c|}{ ADL } & \multicolumn{2}{|c|}{ IADL } & \multicolumn{2}{|c|}{ MMSE } \\
\hline & T0-T1 & T0-Т2 & T0-T1 & T0-T2 & T0-T1 & T0-T2 \\
\hline$t$ & 0.6801 & 1.1056 & 0.6770 & 0.9976 & 0.8431 & 1.1409 \\
\hline$P$ & 0.4968 & 0.2694 & 0.4987 & 0.3190 & 0.3996 & 0.2545 \\
\hline
\end{tabular}

Figure 2 Mean cognitive and funtional parameters over time (with significance table).

Note: Mean cognitive and functional parameters over time (with significance table) in the treatment group.

Abbreviations: ADL, activities of daily living; IADL, instrumental activities of daily living; MMSE, mini mental state examination.

\begin{tabular}{|c|c|c|c|}
\hline Years & T0 & T1 & T2 \\
\hline $65-74$ & 5.0 & 5.1 & 5.1 \\
\hline $75-84$ & 3.4 & 3.6 & 3.7 \\
\hline$\geq 85$ & 3.5 & 3.6 & 3.8 \\
\hline
\end{tabular}

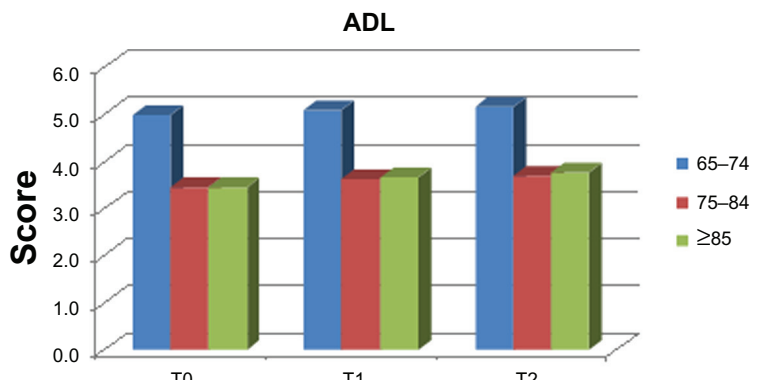

\begin{tabular}{|c|c|c|c|}
\hline Years & T0 & T1 & T2 \\
\hline $65-74$ & 7.3 & 7.7 & 7.9 \\
\hline $75-84$ & 5.5 & 5.8 & 5.9 \\
\hline$\geq 85$ & 6.1 & 6.6 & 6.6 \\
\hline
\end{tabular}

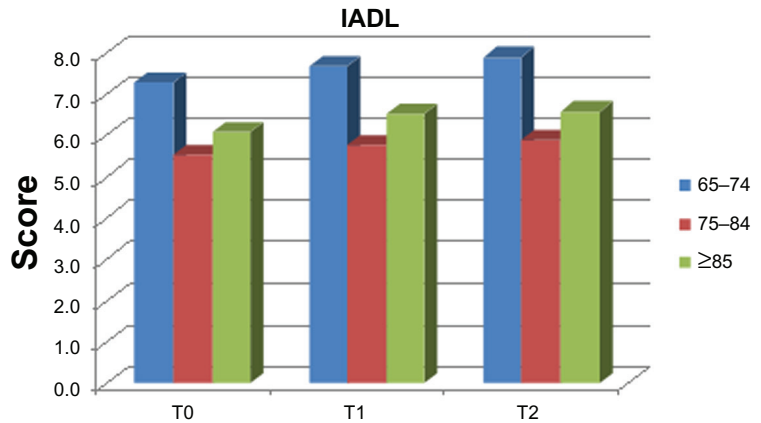

\begin{tabular}{|c|c|c|c|}
\hline Years & TO & T1 & T2 \\
\hline 65-74 & 23.5 & 23.9 & 24.1 \\
\hline $75-84$ & 22.9 & 23.3 & 23.3 \\
\hline$\geq 85$ & 21.8 & 22.1 & 22.2 \\
\hline
\end{tabular}

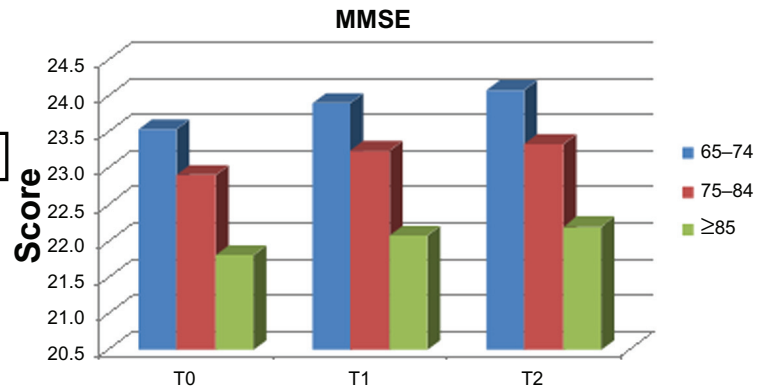

Figure 3 Differences in ADL, IADL and MMSE scores according to age groups.

Notes: Differences in ADL, IADL and MMSE scores according to age groups in the treatment group. T0 = baseline; $\mathrm{TI}=3 \mathrm{months} ; \mathrm{T} 2=9 \mathrm{months}$. Abbreviations: ADL, activities of daily living; IADL, instrumental activities of daily living; MMSE, mini mental state examination. 
A

\begin{tabular}{|c|c|c|c|c|}
\hline MMSEc $^{*}$ & $\begin{array}{c}\text { Citicoline } \\
\text { group } \\
\mathbf{n}=\mathbf{2 6 5}\end{array}$ & $\begin{array}{c}\text { Controls } \\
\mathbf{n}=\mathbf{8 4}\end{array}$ & $t$ & $P$ \\
\hline T0 & $22.4 \pm 4$ & $21.5 \pm 6.9$ & 1.422 & 0.156 \\
\hline T1 & $22.7 \pm 4$ & $20.4 \pm 6.6$ & 3.728 & 0.0001 \\
\hline T2 & $22.9 \pm 4$ & $19.6 \pm 6.3$ & 5.437 & 0.0001 \\
\hline
\end{tabular}

B

MMSE TO

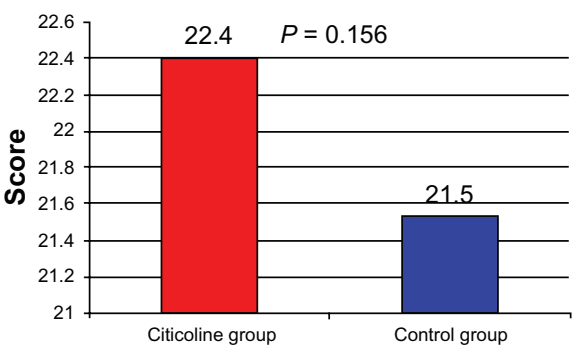

MMSE T2

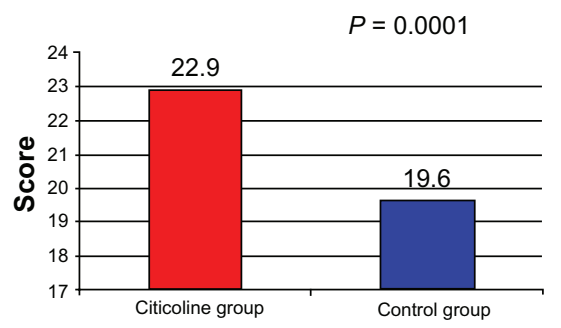

MMSE T1

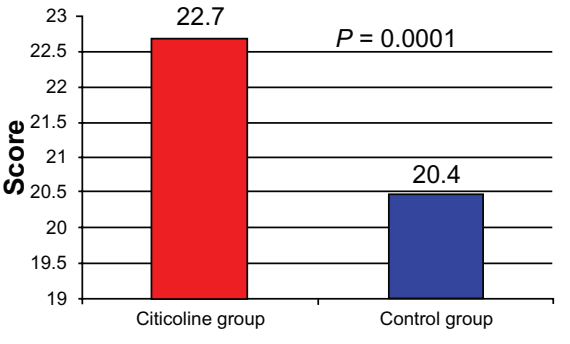

\begin{tabular}{|c|c|c|c|c|}
\hline & \multicolumn{2}{|c|}{$\begin{array}{c}\text { MMSE } \\
\text { Citicoline group }\end{array}$} & \multicolumn{2}{c|}{$\begin{array}{c}\text { MMSE } \\
\text { controls }\end{array}$} \\
\hline & T0-T1 & T0-T2 & T0-T1 & T0-T2 \\
\hline$t$ & 0.863 & 1.439 & 1 & 1.792 \\
\hline$P$ & 0.388 & 0.151 & 0.319 & 0.075 \\
\hline
\end{tabular}

Figure 4 Comparison of corrected MMSE levels between citicoline group and controls.

Notes: ${ }^{* M M S E c}=$ MMSE corrected according to age and education. T0 = baseline; $\mathrm{TI}=3$ months; $\mathrm{T} 2=9$ months.

Abbreviations: MMSE, mini mental state examination; MMSEc, mini mental state examination corrected (for age and education).

In conclusion, our study shows that citicoline is effective and safe in mild vascular cognitive impairment. Further studies are needed to confirm these results and to assess the efficacy and safety of long-term administration of a dietary

ADL

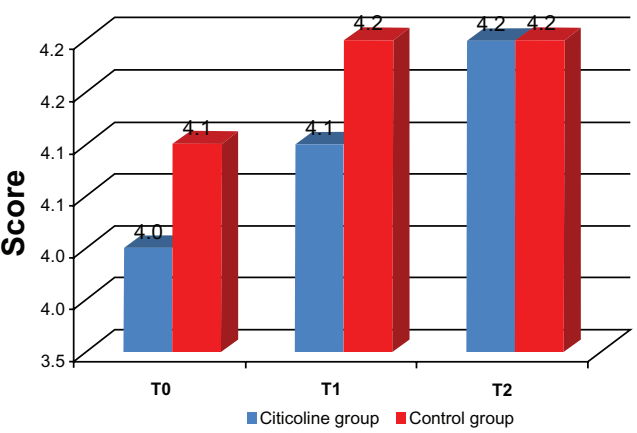

Figure 5 Differences in ADL and IADL scales between the two study groups.

Note: $\mathrm{T} 0$ = baseline; $\mathrm{TI}=3$ months; $\mathrm{T} 2=9$ months

Abbreviations: ADL, activities of daily living; IADL, instrumental activities of daily living. supplement such as CDP choline. Also, it would be interesting to study whether use of citicoline in association with cholinesterase inhibitors may help in delaying the progression of Alzheimer's disease.

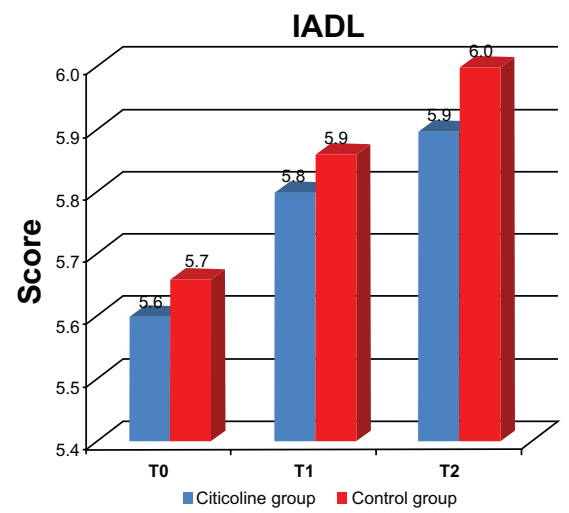




\section{Acknowledgment}

The authors thank Annamaria Squillace for her kind revision of English style and grammar.

\section{Disclosure}

The authors report no conflicts of interest in this work.

\section{References}

1. Jokinen H, Lipsanen J, Schmidt R, et al; LADIS Study Group. Brain atrophy accelerates cognitive decline in cerebral small vessel disease: the LADIS study. Neurology. 2012;78:1785-1792.

2. Román GC, Erkinjuntti T, Wallin A, Pantoni L, Chui HC. Subcortical ischaemic vascular dementia. Lancet Neurol. 2002;1:426-436.

3. Adibhatla RM, Hatcher JF. Citicoline mechanisms and clinical efficacy in cerebral ischemia. J Neurosci Res. 2002;70:133-139.

4. Alvarez XA, Laredo M, Corzo D, et al. Citicoline improves memory performances in elderly subjects. Methods Find Exp Clin Pharmacol. 1997; 19:201-210.

5. Caamano J, Gomez MJ. Effects of CDP-choline on cognition and cerebral hemodynamics in patients with Alzheimer's disease. Methods Find Exp Clin Pharmacol. 1994;16:211-218.

6. Parnetti L, Mignini F, Tomassoni D, Traini E, Amenta F. Cholinergic precursors in the treatment of cognitive impairment of vascular origin: ineffective approaches or need for re-evaluation? J Neurol Sci. 2007; 257:264-269.

7. Cacabelos R, Caamano J. Therapeutic effects of CDP-choline in Alzheimer's disease. Cognition, brain mapping, cerebrovascular hemodynamics and immune factors. Ann N Y Acad Sci. 1996;777:399-403.

8. Fioravanti M, Yanagi M. Cytidine diphosphocholine (CDP-choline) for cognitive and behavioural disturbances associated with chronic cerebral disorders in the elderly. Cochrane Database Syst Rev. 2005; 2:CD000269.

9. Lozano-Fernandez R. Efficacy and safety of oral CDP-choline. Drug surveillance study in 2817 cases. Arzneimittelforschung. 1983; 33(7A):1073-1080.
10. Saver JL. Citicoline: update on a promising and widely available agent for neuroprotection and neurorepair. Rev Neurol Dis. 2008;5: $167-177$.

11. Secades JJ, Frontera G. CDP-choline: pharmacological and clinical review. Methods Find Exp Clin Pharmacol. 1995;17 Suppl B:1-54.

12. Clark WM. Efficacy of citicoline as an acute stroke treatment. Expert Opin Pharmacother. 2009;10:839-846.

13. Hurtado O, Lizasoain I, Moro MA. Neuroprotection and recovery: recent data at the bench on citicoline. Stroke. 2011;42 Suppl 1:S33-S35.

14. Lee HJ, Kang JS, Kim YI. Citicoline protects against cognitive impairment in a rat model of chronic cerebral hypoperfusion. J Clin Neurol. 2009;5:33-38.

15. Secades JJ, Lorenzo JL. Citicoline: pharmacological and clinical review, 2006 update. Methods Find Exp Clin Pharmacol. 2006; 28 Suppl B:1-56.

16. Secades JJ. CDP-choline: update and review of its pharmacology and clinical use. Methods Find Exp Clin Pharmacol. 2002;24 Suppl B:1-53.

17. Secades JJ. CDP-choline and clinical review, 2010 update. Rev Neurol. 2011;52 Suppl 2:S1-S62.

18. Secades JJ. Probable role of citicoline in stroke rehabilitation: review of the literature. Rev Neurol. 2012;54:173-179.

19. Teather LA, Wurtman RJ. Dietary cytidine (5')-diphosphocholine supplementation protects against development of memory deficits in aging rats. Prog Neuropsychopharmacol Biol Psychiatry. 2003;27:711-717.

20. Teather LA, Wurtman RJ. Dietary CDP-choline supplementation prevents memory impairment caused by impoverished environmental conditions in rats. Learn Mem. 2005;12:39-43.

21. Alvarez-Sabin J, Roman GC. Citicoline in vascular cognitive impairment and vascular dementia after stroke. Stroke. 2011;42 Suppl 1:S40-S43.

22. Garcia-Cobos R, Frank-Garcia A, Gutierrez-Fernandez M, DiezTejedor E. Citicoline, use in cognitive decline: vascular and degenerative. Neurol Sci. 2010;299:188-192.

23. Putignano S, Gareri P, Castagna A, et al. Retrospective and observational study to assess the efficacy of citicoline in elderly patients suffering from stupor related to complex geriatric syndrome. Clin Interv Aging. 2012;7:113-118.
Clinical Interventions in Aging

\section{Publish your work in this journal}

Clinical Interventions in Aging is an international, peer-reviewed journal focusing on evidence-based reports on the value or lack thereof of treatments intended to prevent or delay the onset of maladaptive correlates of aging in human beings. This journal is indexed on PubMed Central, MedLine, the American Chemical Society's 'Chemical Abstracts

\section{Dovepress}

Service' (CAS), Scopus and the Elsevier Bibliographic databases. The manuscript management system is completely online and includes a very quick and fair peer-review system, which is all easy to use. Visit http://www.dovepress.com/testimonials.php to read real quotes from published authors. 